\title{
Counter-current separation of cobalt(II)-nickel(II) from aqueous sulphate media with a mixture of Primene JMT-Versatic 10 diluted in kerosene
}

\author{
N. Belhadj, T. Benabdallah, M. T. Coll, A. Fortuny, M. Hadj Youcef \& A. M. \\ Sastre \\ To cite this article: N. Belhadj, T. Benabdallah, M. T. Coll, A. Fortuny, M. Hadj Youcef \& A. M. \\ Sastre (2020) Counter-current separation of cobalt(II)-nickel(II) from aqueous sulphate media with \\ a mixture of Primene JMT-Versatic 10 diluted in kerosene, Separation Science and Technology, \\ 55:3, 513-522, DOI: 10.1080/01496395.2019.1577271
}

To link to this article: https://doi.org/10.1080/01496395.2019.1577271

\section{Counter-current separation of cobalt(II)-nickel(II) from aqueous sulphate media with a mixture of Primene JMT-Versatic 10 diluted in kerosene}

\begin{abstract}
N. Belhadj ${ }^{a, c}$, T. Benabdallaha, M. T. Coll ${ }^{b}$, A. Fortuny ${ }^{c}$, M. Hadj Youcefa, and A. M. Sastre ${ }^{d}$

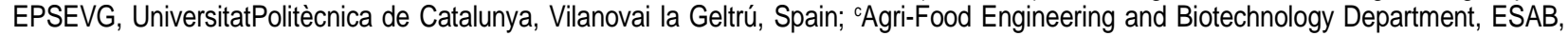
Barcelona, Spain

ABSTRACT

This work claims the use of the mixture of Primene ${ }^{\circledR} \mathrm{JMT}-$ Versatic $10\left[\mathrm{HJMT}^{+} \cdot\right.$ Versatic $\left.{ }^{-}\right]$IL diluted in Kerosene as an extractant for cobalt/nickel separation from sulphate media by solvent extraction technique, its application on a continuous counter-current device is possible because the presence of Primene ${ }^{\circledast} \mathrm{JMT}$ in the organic phase allows us to maintain the $\mathrm{pH}$ of the equilibrated aqueous phase at an almost stable value. The solvent extraction of cobalt and nickel ions is studied as a function of the extractant concentration in the organic phase and the concentration of both metals. By constructing the McCabe-Thiele diagram, we found that four steps are necessary to separate the cobalt(II) from the nickel(II) in sulphate media. A simulated continuous counter-current experiment corroborated the McCabe-Thiele predictions, obtaining a raffinate containing $83 \%$ of the inlet nickel with a purity of $99.9 \%$, working with an A:O ratio $1: 2$.
\end{abstract}

aLaboratoire de Chimie et d'Electrochimie des Complexes Métalliques (LCECM), Département de Chimie Organique Industrielle, Faculté de Chimie, Université des Sciences et de la Technologie d'Oran-Mohamed Boudiaf (USTOMB), Oran, Algérie; 'Chemical Engineering Department, UniversitatPolitècnica de Catalunya, Castelldefels, Spain; ${ }^{\mathrm{d}}$ Chemical Engineering Department, ETSEIB, UniversitatPolitècnica de Catalunya,

Accepted 3 January 2019

Mixture extractants; ionic liquid; continuous counter- current; cobalt; nickel; sulphate media Introduction

Cobalt and nickel are two important metals because they are extensively applied in different branches of industry such as superalloys in aerospace, gas turbine engines, automotive, military, electronics and catalyst in the petroleum industry, moreover as pigments in ceramics, glass, plastic materials, magnets, electroplat-

ing and other chemical applications, but their main

market is the battery components. ${ }^{[1]}$ Nowadays, cobalt is included in the list of critical raw materials (CRMs) created by the European Commission, which combines, to each material, the economic importance for the EU with its supply risk (Report on Critical Raw Materials for The $\mathrm{EU}^{[2]}$ ). In this sense, it is forecasted that the refined cobalt world supply growth will increase at a lower rate than the cobalt world consumption, which is mainly due to the strong growth in the rechargeable

batteries and aerospace industries. ${ }^{[1]}$ In fact, about $4.5^{-}$

$8 \%$ per year is the demand growth expected until 2020

(Report on Critical Raw Materials for The $\left.\mathrm{EU}^{[2]}\right)$. In the

near future, the natural resources of these metals could be insufficient and expensive to supply this strong demand.

According to the European Directive 2006/66/CE and

considering the extensive use of batteries as green energies in the electronic devices and also in the hybrid or electric vehicles, it is needed to develop specific routes to recovery the valuable metals prior to a safe disposal. In this way, these processes will be worthwhile economically and environmentally favoured. These processes include the 
the supercritical fluids for metal leaching and extraction and the solvent extraction. ${ }^{[5-13]}$

Spent catalysts and waste alloys are recognized as secondary sources of these metals. The use and exploi- tation of these other secondary sources to metal recov- ery gives rise to the interest for more intensive cobalt and nickel separation processes. ${ }^{[14-18]}$

So far, many achievements for cobalt or nickel enrich- ment are made in the field of solid-phase extraction ${ }^{[19]}$ [20]

cloud point extraction,

salting-out liquid-liquid

extraction, ${ }^{[21]}$

adsorption, ${ }^{[22]}$

[24]

liquid membranes, ${ }^{[23]}$

micro-

[25]

emulsion extraction

and hollow fibre membranes.

Liquid-liquid (i.e., solvent) extraction continues represent- ing a separation technology of significance in both metal ion separations and commercial scale separation

CONTACTN.Belhadj nadia.belhadj@univ-usto.dz; M.HadjYoucef hadjyoucef.mohamed@yahoo.fr Laboratoire de Chimieetd'Electrochimiedes Complexes Métalliques (LCECM), Département de Chimie Organique Industrielle, Faculté de Chimie, Université des Sciences et de la Technologie d'OranMohamed Boudiaf (USTOMB), BP-1505 EL-M'naouer, Oran, Algeria.

Color versions of one or more of the figures in the article can be found online at www.tandfonline.com/lsst. SEPARATION SCIENCE AND TECHNOLOGY

2020, VOL. 55, NO. 3, 513-522

https://doi.org/10.1080/01496395.2019.1577271

(c) 2019 Taylor \& Francis Group, LLC

514

M. HADJ YOUCEF ET AL.

processes. ${ }^{[26]}$ Solvent extraction offers some advantages over competing techniques, like the flexibility of the chem- istry employed in the extraction process (e.g., nature and concentration of extractant, aqueous phase composition) and the concomitant "tailorability" of the separations, account for the ongoing popularity of the technique.

The published literature data gave big attention to the separation of cobalt and nickel and most of these studies used cationic extractants such as Cyanex 272, Versatic10 acid, D2EHPA, PC88A, etc. ${ }^{[6,27-35]}$ When cationic extractants are used in a counter-current

extraction process, the aqueous phase $\mathrm{pH}$ decreases, the $\mathrm{pH}$ of the aqueous phase decreases, making the

are shown in Table 1. Kerosene, which is supplied by Sigma Aldrich, is used as the diluent. $\mathrm{CoSO}_{4}, \mathrm{NiSO}_{4}$ and $\mathrm{Na}_{2} \mathrm{SO}_{4}$ are obtained from Panreac Applichem and all the used chemicals are analytical reagent grade. The $\mathrm{Na}_{2} \mathrm{SO}_{4}$ is used to adjust the sulphate concentration at

$0.5 \mathrm{M}$ in all experiments. To make the stripping, a solu-tion $1 \mathrm{M}$ of the $\mathrm{H}_{2} \mathrm{SO}_{4}$ is used.

The extractant used in this work is prepared by mixing

equimolar quantities of Primene $\mathbb{J} \mathrm{JMT}\left(\mathrm{RNH}_{2}\right.$, basic char- acteristic) and Versatic10 (HA, acidic properties) at room temperature $\left(22 \pm 2^{\circ} \mathrm{C}\right.$ ) (Fig. 1). The acid-base reaction that takes place between these compounds is as follows:

metal transfer to the organic phase impossible without

$$
R N H_{2 \text { ðorgp }} \mathbf{p} H A_{\text {ðorg }} \mathbf{I} R H^{\mathrm{p}}
$$

$\mathrm{pH}$ readjusting. One way to avoid this problem is the use of bifunctional ionic liquids as selective extractant agents because they are compatibles with the continu- ous counter-current conditions. The possibility to com- bine different cation/anion pairs to develop new ionic liquids for specific tasks promoted their extensive use 
in the field of the metal ion separations.

This work presents the extraction and separation of cobalt(II) and nickel(II) from sulphate media using the acidbase couple $\left[\mathrm{HJMT}^{+}\right.$Versatic10 $]$as a tailored

extractant. The purpose is to produce an ionic liquid able to make the selective separation of cobalt(II)/nickel

(II) from an aqueous sulphate solution using a continuous counter-current extraction process without conditioning the inter-step pHs. The study of the JMT/Versatic ratio in the mixture and the concentration of the extractant allow us to find the best conditions to carry out the separation. The procedure to simulate the counter-current process using separatory funnels is an improvement comparing to the methodology applied in other studies and allows a reduction in the needed phase volumes.

\section{Experimental}

\section{Reagents}

The neodecanoic acid, commercially known as Versatic 10 Acid (Versatic) and Primene®JMT (JMT), a tertiary alky $\left(\mathrm{C}_{16}-\mathrm{C}_{22}\right)$ primary amine are kindly donated from Momentive Specialty Chemicals and Dow Chemical, respectively. The physical properties of both compounds

$$
3 \cdot A_{\text {ðorg } \mathrm{p}}
$$

This reaction allows the formation of the stable ion- pair arrangement which is able to extract $\mathrm{Co}(\mathrm{II})$ and $\mathrm{Ni}$ (II) from the aqueous media conditions proposed in this work. The obtained extractant is diluted in Kerosene until the decided concentrations.

\section{Solvent extraction}

Bearing in mind that the objective of this paper is the $\mathrm{Co}(\mathrm{II}) / \mathrm{Ni}(\mathrm{II})$ separation, the working conditions were established on the basis industrial applications. So, the feed solution contained $500 \mathrm{mg}$ Co (II)/L and $5000 \mathrm{mg}$ $\mathrm{Ni}(\mathrm{II}) / \mathrm{L}$ in $0.5 \mathrm{M} \mathrm{SO}^{2-}$. These metal ion concentrations are chosen because the Co(II): Ni(II) concentration ratio is usually 1:10 (mg/L) in the real leachings. ${ }^{[52]}$

Equal volumes of aqueous and organic phases are mixed in a separatory funnel and are maintained under agitation at room temperature $\left(22 \pm 2^{\circ} \mathrm{C}\right)$. After $20 \mathrm{~min}$ of agitation in a horizontal mechanical shaker (SBS Mechanical Shaker), a sample is taken from the aqu- eous phase to determine the metal concentrations by inductively coupled plasma Atomic Emission Spectroscopy using a 4100 MP-AES spectrophotometer (Agilent Technologies). The concentrations of metal ions in the organic phase are calculated from the dif- ference between the metal concentration in the aqueous phase before and after extraction. Then, the loaded organic phases are stripped, using the same extraction procedure, with $1 \mathrm{M} \mathrm{H}_{2} \mathrm{SO}_{4}$, and the metal concentra- tion in this solution allows us to close the mass balance.

4

Table 1. Physical properties of the IL precursors.

Commercial name Content, \% Avg. mol. weight, $\mathrm{g} / \mathrm{mol}$ Acidvalue, $\mathrm{mgKOH} / \mathrm{g}$ Neutral equivalent, g/mol Density, $\mathrm{kg} / \mathrm{m}^{3} \mathrm{Viscosity}, \mathrm{mPa} . \mathrm{s}$

4

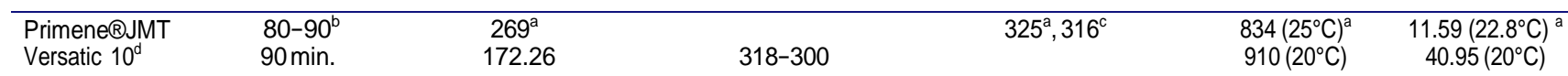

${ }^{\mathrm{a}}$ Technical data sheet Primene J-MT, Global CTM. ${ }^{[49]}$

${ }^{\mathrm{b}}$ Technicaldata sheet Primene J-MT, Dow Chemical Company. ${ }^{[50]}$

${ }^{\mathrm{c}}$ Experimental data by potentiometric titration in water/ethanol.

${ }^{\mathrm{d}}$ Technicaldata sheet Versatic acid 10, Hexion. ${ }^{\left[{ }^{11}\right]}$

$\mathrm{O}$

$$
\mathrm{NH}_{3}{ }^{+}{ }^{-} \mathrm{O}
$$

Figure 1. Structure of $\left[\mathrm{HJMT}^{+}\right.$Versatic $] \mathrm{IL}$.

The extraction yield $(\% \mathrm{E})$, the distribution coeffi- cient (D) and the separation factor $(\boldsymbol{\beta})$ are defined as follows: 
order to make a multistep counter-current extraction pro- cess, the equilibrium metal distribution (isotherm) and the mass balances are required. The simulation of the contin- uous counter-current process is done using a set of separa- tory funnels. Figure 2 shows a conceptual scheme of the counter-current contacts during the transitory period until to achieve the steady-state conditions. The methodology depicted in allows minimizing the volume of solutions

required to carry out the counter-current simulation. Also, compared to other procedures in the literature ${ }^{[53,54]}$, this reduces the number of used funnels to accomplish the steady-state for the same number of the separation steps.

\section{E\% $1 / 4$}

$\left.1 / 2 M^{\mathrm{p} 2}\right]_{i n i}$

$\left.1 / 2 M^{\mathrm{p} 2}\right]_{\text {org }}$

$\times 100$

To begin the process, $14 \mathrm{~mL}$ of organic phase $(0.47 \mathrm{~mol} / \mathrm{L}$ JMT-Versatic IL) and $7 \mathrm{~mL}$ of aqueous phase $(500 \mathrm{mg} / \mathrm{L}$ of $\mathrm{Co}(\mathrm{II})-5000 \mathrm{mg} / \mathrm{L}$ of $\mathrm{Ni}(\mathrm{II})$ in

$0.5 \mathrm{M}$ of sulphate medium) at $\mathrm{pH} 6.2$ are contacted in four separatory funnels, shaken for 20 min and let

D

$$
\left.1 / 2 M^{\mathrm{p} 2}\right]_{a q}
$$

(2)

(3)

stand until both phases are completely separated. Once the phases are separated, it must perform the following procedure:

- Take a new separatory funnel (the separatory funnel

$1 / 4$

D

where $\left[\mathrm{M}^{+2}\right]_{\text {ini }},\left[\mathrm{M}^{+2}\right]_{\mathrm{aq}}$ and $\left[\mathrm{M}^{+2}\right]_{\text {org }}$ represent the initial, the equilibrium and the organic metal concen- trations, respectively.

\section{Counter-current extraction}

To use the bifunctional JMT/Versatic ionic liquid proposed in this work for the Co(II)/Ni(II) separation at these con- ditions will be necessary more than a simple contact. In

$1 / 4$

D

5 in Fig. 2) and introduce a fresh organic phase

- Take out the aqueous phase of the funnel 4 as a raffinate

- Transfer the aqueous phase from the separatory funnel 3 to the funnel 5,2 to 4 and 1 to 3 and introduce a fresh aqueous phase in the funnel 2

- Put aside the separatory funnel 1 and keep the organic phase to make the stripping.

- Place the other funnels to shake for $20 \mathrm{~min}$ 
Figure 2. Scheme of the methodology applied to simulate the four stages of counter-current extraction process.

This procedure is repeated until the process stabilization, in fact is running 11 times to reach it. At this point, all the aqueous phases are collected and all the loaded organic phases are twice stripped with $\mathrm{H}_{2} \mathrm{SO}_{4} 1 \mathrm{M}$. The samples are analysed to determine the metal concentrations of the raffinate and the extract of each one of the four stages needed for the metal ion separation process.

\section{Results and discussion}

\section{Effect of the JMT concentration on the separation of cobalt and nickel}

To determine the JMT/Versatic ratio in the extractant that promotes the best selectivity to the Co(II)/Ni(II) separa- tion, different organic phases containing a fixed concentra- tion of Versatic $(10 \%(\mathrm{v} / \mathrm{v}))$, and JMT concentration in the range 0 to $25 \%$ (v/v) are prepared. Figure 3 shows the effect of this parameter on the Ni/Co extraction when the aqu- eous phase contains $500 \mathrm{mg} / \mathrm{L}$ of cobalt(II) and $5000 \mathrm{mg} / \mathrm{L}$ of nickel(II) in $0.5 \mathrm{M}$ of sulphate media. It can be observed that the extraction percentage of cobalt increases when the JMT concentration in the extractant is increased whereas in the case of the nickel, the percentage of extraction barely rises and it achieves only 15-18\%. Also, it can be seen that low extraction yields for both metal ions are obtained by using Versatic 10 acid 10\% (v/v) alone. In fact, it is neces- sary to increase the JMT concentration beyond $5 \%$ to have significant extraction of the metal ions. This behaviour is due to the low equilibrium $\mathrm{pH}$ of the aqueous phase, which is equal to 4.4, compared to the $\mathrm{pH}$ of the initial solution, equal to 6.2. Therefore, the addition of JMT neutralizes this effect and makes possible the metal extraction possible. In Fig. 3, it is possible to appreciate the increase in the $\mathrm{Co}(\mathrm{II})$ extraction from the mixture by the addition of JMT linked

to the rise in equilibrium $\mathrm{pH}$ of the aqueous phase from 6.4 to $\mathrm{pH} 7.4$.

On the other hand, the separation factor represented in Fig. 4 increases to the maximum value of 10.2. It corresponds to a JMT concentration equal to $18 \%(\mathrm{v} / \mathrm{v})$ and for higher concentrations of JMT, $\beta$ remains con- stant. This result suggests that 18\% JMT-10\% Versatic is the ideal IL composition able to separate Co (II) from Ni (II) in the mixture and it corresponds to a $0.47 \mathrm{M}$ of each constituent in the binary mixture (equimolar ratio).

\section{Effect of the ionic liquid concentration on the cobalt/nickel separation}

After determining that the optimal JMT/Versatic molar ratio producing the extractant is equal to 1, the effect of $\left[\mathrm{HJMT}^{+}\right.$Versatic $\left.{ }^{-}\right]$IL concentration on the extraction of

Figure 4. Effect of the JMT concentration on the separation factor using constant $10 \%(\mathrm{v} / \mathrm{v})$ of Versatic 10 acid in kerosene. Aqueous phase: $500 \mathrm{mg} / \mathrm{L}$ of $\mathrm{Co}(\mathrm{II})$ and $5000 \mathrm{mg} / \mathrm{L}$ of $\mathrm{Ni}(\mathrm{II})$ in

$0.5 \mathrm{M}$ sulphate solution and $\mathrm{pH} 6.2$.

Figure 3. Effect of the JMT concentration on the extraction of $\mathrm{Co}(\mathrm{II})$ and $\mathrm{Ni}(\mathrm{II})$ and $\mathrm{pH}$ of the equilibrated aqueous phase maintaining $10 \%(\mathrm{~V} /$ v) of Versatic10acidin kerosene. Aqueousphase: $500 \mathrm{mg} / \mathrm{L} \mathrm{of} \mathrm{Co(II)} \mathrm{and} 5000 \mathrm{mg} / \mathrm{L} \mathrm{of} \mathrm{Ni(II)} \mathrm{in} \mathrm{0.5M} \mathrm{sulphate} \mathrm{solutionandpH6.2.}$

cobalt and nickel ions from the mixture is studied in the range 0.1-0.8 M. As can be seen in Fig. 5, the extraction of cobalt(II) increases as the extractant concentration increases, while nickel extraction does not appear to be

Versatic 10 (HA), it is well known that the extrac- tion process promotes a reduction of the $\mathrm{pH}$ in the aqueous phase because of the cationic exchange reaction:

influenced by the variation of the $\left[\mathrm{HJMT}^{+}\right.$Versatic $\left.{ }^{-}\right]$. Also, Fig. 5 shows an almost stable $\mathrm{pH}$ of the equilibrated aqu-

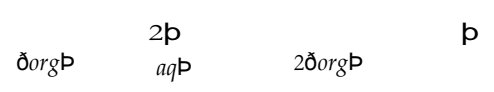


eous phase for all the organic solutions used because the ratio between both components of the mixture JMT/ Versatic is maintained. Figure 6 demonstrates that the maximum separation factor are obtained using $0.47 \mathrm{M}$ of ionic liquid. This concentration is the best to separate cobalt from nickel and therefore it is chosen for the sub- sequent experiments.

\section{Chemical extraction mechanism}

Extraction and separation of the $\mathrm{Co}(\mathrm{II}) / \mathrm{Ni}(\mathrm{II})$ in the

\section{$2 H A \quad \mathbf{p} M \quad \mathbf{I} M A \quad \mathbf{p} 2 H$}

this behaviour prevents its use as extractant in a con- tinuous process without inter-steps conditioning. On the other hand, the extraction of $\mathrm{Co}(\mathrm{II})$ or $\mathrm{Ni}(\mathrm{II})$ with the primary amine JMT generates a precipitate in the organic phase and this makes the separation impossible.

The mixture of the amine with the Versatic 10 pro- motes the IL formation, $\mathrm{RNH}_{3}{ }^{+} \mathrm{A}^{-}$, and this compound modifies the extraction mechanism as can be seen in these two options:

$2 H A \quad \mathbf{p} M \quad \mathbf{I} M A \quad \mathbf{p} 2 H$

experimental conditions depicted in this study pre-

$2 H A \quad \mathbf{p} M \quad \mathbf{I} M A \quad \mathbf{p} 2 H$

$2 R N H^{p}$

$2 H A \quad \mathbf{p} M \quad \mathbf{I} M A \quad \mathbf{p} 2 H$

$2 \mathrm{p} \quad 2$

$2 H A \quad \mathbf{p} M \quad \mathbf{I} M A \quad \mathbf{p} 2 H$

sent some problems. For a cationic extractant like

$2 H A \quad \mathbf{p} M \quad \mathbf{I} M A \quad \mathbf{p} 2 H$

or:

$2 H A \quad \mathbf{p} M \quad \mathbf{I} M A \quad \mathbf{p} 2 H$

$\cdot M A_{2 \text { боrg口 }}$

$2 H A \quad \mathbf{p} M \quad \mathbf{I} M A \quad \mathbf{p} 2 H$

$2 R N H^{\mathrm{b}} A$

$2 H A \quad \mathbf{p} M \quad \mathbf{M} A \quad \mathbf{p} 2 H$

$\mathrm{p} M^{2 \mathrm{p}}$ 
0

$\mathrm{pSO} \mathrm{O}^{2}$

$2 H A \quad \mathbf{p} M \quad \mathbf{I} M A \quad \mathbf{p} 2 H$

0

I $M A_{2 \text { org }}$

$2 H A \quad \mathbf{p} M \quad \mathbf{I} M A \quad \mathbf{p} 2 H$

0

3 ðorgp

$2 H A \quad \mathbf{p} M \quad \mathbf{I} M A \quad \mathbf{p} 2 H$

ðapp

$2 H A \quad \mathbf{p} M \quad \mathbf{I} M A \quad \mathbf{p} 2 H$

0

4 ðaq $\quad$ ๖ $\mathrm{P}$

$2 H A \quad \mathbf{p} M \quad \mathbf{I} M A \quad \mathbf{p} 2 H$

0

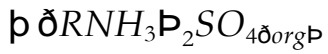

The $\mathrm{pH}$ in the aqueous phase for both proposed mechanisms is maintained and the continuous extraction can take place.

The experimental data fit very well with the mechanism of the reaction (6). Equation (7) depicts the extraction constant corresponding at this reaction:

${ }_{\left.1 / 2 M A_{2}\right]}\left({ }_{R N H_{3}} \mathrm{P}_{2} \mathrm{SO}_{4}\right.$

$2 H A \quad \mathbf{p} M \quad \mathbf{I} M A \quad \mathbf{p} 2 H$

0

$\operatorname{Kext}^{1 / 4}{ }^{1 / 4} H^{p} \quad 2$

$2 H A \quad \mathbf{p} M \quad \mathbf{I} M A \quad \mathbf{p} 2 H$

0

(7)

$2 H A \quad \mathbf{p} M \quad \mathbf{I} A \quad \mathbf{p} 2 H$ 
Figure 5. Effect of the $\left[\mathrm{HJMT}^{+} \mathrm{Versatic}\right] \mathrm{IL}$ concentration on the $\mathrm{Co}(\mathrm{II})$ and $\mathrm{Ni}(\mathrm{II})$ extraction and the $\mathrm{pH}$ of the equilibrium. Aqueous phase: $500 \mathrm{mg} / \mathrm{L}$ of $\mathrm{Co}(\mathrm{II})$ and $5000 \mathrm{mg} / \mathrm{L}$ of $\mathrm{Ni}(\mathrm{II})$ in $0.5 \mathrm{M}$ sulphate solution and $\mathrm{pH}$ 6.2. JMT/Nersatic molar ratio equal to 1.

\section{$2 H A \quad \mathbf{p} M \quad \mathbf{I} M A \quad \mathbf{p} 2 H$}

\section{${ }_{3} A$ ] $\left.1 / 2 M^{2 b}\right] S O^{2}$ ]}

where the terms in brackets represent the equilibrium concentrations of the compounds. Considering that $\left[\mathrm{MA}_{2}\right]$ must be equal to $\left[\left(\mathrm{RNH}_{3}\right) \mathrm{SO}_{4}\right]$ and linearizing Equation (7) can be obtained as follows:

$2 \mathrm{p} 2$

$2 H A \quad \mathbf{p} M \quad \mathbf{I} M A \quad \mathbf{p} 2 H$

0

th

4

$\log ^{1 / 2 M}$

$2 H A \quad \mathbf{p} M \quad \mathbf{I} M A \quad \mathbf{p} 2 H$

42

]$_{\text {ðorg }}$

$2 H A \quad \mathbf{p} M \quad \mathbf{I} M A \quad \mathbf{p} 2 H$

0

th

4

$2 \log R N H^{\mathrm{p}} A$

$2 H A \quad \mathbf{p} M \quad \mathbf{I} M A \quad \mathbf{p} 2 H$

0

42

$\log$ Kext

$2 H A \quad \mathbf{p} M \quad \mathbf{I} M A \quad \mathbf{p} 2 H$ 
0

12

4

$\left.1 / 2 M^{2 b}\right]_{a q}^{1 / 4}$

$2 H A \quad \mathbf{p} M \quad \mathbf{I} A \mathrm{p} 2 \mathrm{H}$

th

4

$\begin{array}{llll}3 & p & p & 4\end{array}$

$2 H A \quad \mathbf{p} M \quad \mathbf{I} M A \quad \mathbf{p} 2 H$

d

th.

o p

and as can be seen in Fig. 7, for the Co(II) extraction, the straight line obtained by plotting $\log \left(\left[\mathrm{Co}^{2+}{ }_{(\text {org })}\right]^{2} /\right.$

$2 H A \quad \mathbf{p} M \quad \mathbf{I} A \quad \mathbf{p} 2 H$

0

4

o

$\left[\mathrm{Co}^{2+}\right.$

$2 H A \quad \mathbf{p} M \quad \mathbf{I} M A \quad \mathbf{p} 2 H$

0

4

$\circ \mathrm{p}$

]) versus $\log \left[\mathrm{RNH}^{+} \mathrm{A}^{-}\right]$has a slope value

$2 H A \quad \mathbf{p} M \quad \mathbf{M} A \quad \mathbf{p} 2 H$ 
equal to 2. This suggests that the extraction mechanism of $\mathrm{Co}(\mathrm{II})$ corresponds to the model proposed in Equation (6).

$2 H A \quad \mathbf{p} M \quad \mathbf{I} M A \quad \mathbf{p} 2 H$

Figure 6. Effect of the $\left[\mathrm{HJMT}^{+}\right.$Versatic] IL concentration on the separation factor. Aqueous phase: $500 \mathrm{mg} / \mathrm{L}$ of $\mathrm{Co}(\mathrm{II})$ and $5000 \mathrm{mg} / \mathrm{L}$ of $\mathrm{Ni}(\mathrm{II})$ in $0.5 \mathrm{M}$ sulphate solution and pH6.2. JMT/Nersatic molar ratio equal to 1.

Effect of the CO/NI ratio on the separation of cobalt and nickel

On the other hand, this study also carried out the individual metal ions, $500 \mathrm{mg} / \mathrm{L} \mathrm{Co(II)} \mathrm{and} 5000 \mathrm{mg} /$

Despite these last results, where low $\mathrm{Ni}(\mathrm{II})$ concentration in the mixture allows us to get better cobalt extraction, to make the separation, a solution containing relatively a high concentration of nickel (Co/Ni 1:10) is chosen because this ratio is often found in industrial applications.

Figure 7. Plot of $\log \left(\left[\mathrm{Co}^{2+}\right.\right.$

(org)] /[Co

(aq)]) vs. $\quad \log$

\section{Isotherm extraction}

The equilibrium isotherm for the extraction of the individual metals ions as well as the extraction isotherm of the cobalt(II) in mixtures containing a constant concentration of nickel(II) (5000 mg/L) as shown in Fig. 9. The concentration of the ionic liquid is $0.47 \mathrm{M}$ and the aqueous solutions contain metals ions in the 
$\mathrm{L} \mathrm{Ni(II),} \mathrm{and} \mathrm{for} \mathrm{a} \mathrm{cobalt(II)/nickel(II)} \mathrm{mixture} \mathrm{con-} \mathrm{taining} 500 \mathrm{mg} / \mathrm{L}$ of each metal. The results in Fig. 8 indicate that the percentage of extraction in the case of cobalt alone and nickel alone increases by increas- ing $\left[\mathrm{HJMT}^{+}\right.$Versatic $\left.{ }^{-}\right] \mathrm{IL}$ even though cobalt is more influenced by this variable than the nickel. The observed extraction behaviour for the cobalt ion from the mixtures (with a ratio 1:1 and 1:10 w/w) is the same that it shows individually, but as can be seen in this figure, the extraction percentage increment is higher in the case of $\mathrm{Co}$ (II) from the mixture $\mathrm{Co} / \mathrm{Ni}$ ratio of 1:1 compared to the $\mathrm{Co}(\mathrm{II})$ from the mixture $\mathrm{Co} / \mathrm{Ni}$ ratio of 1:10. Independently on the extractant concentration, the extraction percentage of nickel(II) from the mixtures is maintained near to $10 \%$, a value smaller than it gets for $\mathrm{Ni}$ (II) alone. The cobalt ion is preferentially extracted from the mixture, but the presence of a high amount of nickel makes it more difficult.

$2 \quad 2+$

range $50-5000 \mathrm{mg} / \mathrm{L}$ in $0.5 \mathrm{M}$ of $\mathrm{SO}_{4}^{2}$.

In all the cases, the equilibrium $\mathrm{pH}$ is in the range 7.2-7.3. For the individual metal ions, this figure shows again that the cobalt extraction gives better yields than the nickel extraction.

Comparing the cobalt isotherms, we can see that the presence of $5000 \mathrm{mg} / \mathrm{L}$ of nickel(II) (constant concentra- tion) in the feed solution decreases the extraction of $\mathrm{Co}$ (II). In the same experiments, the concentration of $\mathrm{Ni}$ (II) in the organic phase decreases when the concentration of cobalt ion in the aqueous phase increases. This behaviour can be observed in Fig. 10 and it suggests that the preferential extraction of $\mathrm{Co}$ (II) hinders the extraction of $\mathrm{Ni}$ (II) and this fact will be exploited in the counter-current process.

\section{Counter-current extraction}

The McCabe-Thiele graphical method was used to calcu- late the number of theoretical equilibrium steps for the separation of $\mathrm{Co}(\mathrm{II})$ from the mixture using $0.47 \mathrm{M}$ of IL. According to this method, the distribution equilibrium curve of the cobalt (isotherm) in the working range

Figure 8. Effect of the $\left[\mathrm{HJMT}^{+}{ }^{\vee}\right.$ ersatic $\left.{ }^{-}\right] \mathrm{IL}$ concentration on the $\mathrm{Co}(\mathrm{II})$ and $\mathrm{Ni}(\mathrm{II})$ extraction for the individual metal ion and for the mixtures of the $1: 1$ and 1:10 Co/Ni ratios.

$2 \quad 2+$

Figure 9. Extraction isotherms for individual metal ion and for $\mathrm{Co}(\mathrm{II})$ in the mixture with $5000 \mathrm{mg} / \mathrm{L}$ of $\mathrm{Ni}(\mathrm{II})$. Aqueous phase: $0.5 \mathrm{M}$ sulphate solution. Organic phase: $0.47 \mathrm{M}$ of the IL.

SEPARATION SCIENCE AND TECHNOLOGY

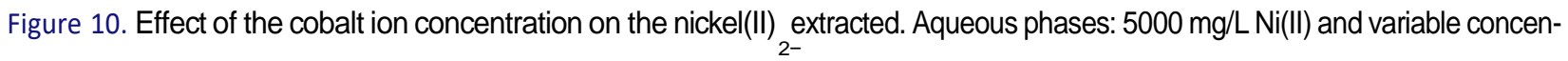

Figure 12. Evolution of the $\mathrm{Co}(\mathrm{II})$ and $\mathrm{Ni}(\mathrm{II})$ concentrations during the transitory period up to the steady state.

tration of $\mathrm{Co}(\mathrm{II})$ in $0.5 \mathrm{MSO}_{4}$

. Organic phase: $0.47 \mathrm{M}$ of the IL.

state conditions are given in the scheme in Fig. 13. The metal ion concentrations obtained experimentally

$(0-500 \mathrm{mg} / \mathrm{L})$ and the mass balance line at a phase ratio A: O of 1:2 are represented in Fig. 11. Taking in consideration that the aim of this work is to separate the Co(II) from a mixture containing $5000 \mathrm{mg} / \mathrm{L}$ of nickel(II), constructing the McCabe-Thiele diagram confirms that four counter- current steps will be necessary.

The counter-current experiment is carried out by the procedure and at the conditions depicted previously in the experimental section. To be sure that the steady-state has achieved, 14 runs were done. The evolution of $\mathrm{Co}$ (II) and $\mathrm{Ni}$ (II) concentrations in the fourth stage raffinate during the transitory period as shown in Fig. 12. We can see, after 11 runs, that the concentrations of these metal ions are constants $(2 \mathrm{mg} / \mathrm{L}$ and near $4100 \mathrm{mg} / \mathrm{L}$, respectively) mean- ing that 11 runs would be enough to achieve the steady- state.

The nickel(II) and cobalt(II) concentrations and the pHs obtained in each one of the four stages of the counter-current process after achieving the steady- 
are in concordance with the values predicted by the McCabe-Thiele method and it can be seen in Fig. 11 where the experimental points are included as bold ticks. It is noticeable that the Co(II) concentration in the raffinate is reduced from 500 to $2 \mathrm{mg} / \mathrm{L}$, obtaining a flow rich in nickel $(99,95 \%)$ and practically cobalt free. These results indicate a good separation between nickel and cobalt using this ionic liquid in a four steps coun- ter-courrent extraction process. As can be observed in

Fig. 13, the extraction by [HJMT ${ }^{+}$Versatic $\left.{ }^{-}\right]$IL allows

us to maintain the $\mathrm{pH}$ nearly constant during the separation process avoiding the addition of an alkali to condition the aqueous phases. This is a great advan- tage via other extraction systems used to separate this challenging mixture.

\section{Conclusions}

In this article, an improvement on the separation of cobalt from nickel in sulphate medium is carried out using the cheap $\mathrm{HJMT}^{+}$Versatic ${ }^{-}$ionic liquid.

The more important points that can be drawn from this work are as follow:

- Stoichiometric JMT/Versatic mixtures allow us to maintain the $\mathrm{pH}$ nearly constant during the coun- ter-current process without conditioning the aqu- eous phases.

- The optimal concentration of the $\left[\mathrm{HJMT}^{+}\right.$Versatic $]$IL to carrying out the Co (II)/ Ni (II) separation is 0.47 $\mathrm{mol} / \mathrm{L}$.

- The applied counter-current procedure enables the reduction of the amount of the required reagents to simulate the separation process.

Figure 13. Concentration of the $\mathrm{Co}(\mathrm{II})$ and $\mathrm{Ni}(\mathrm{II})$ in each stage of the counter-current extraction process. $\mathrm{A}: \mathrm{O}$ ratio $=1: 2$. Feed solution $500 \mathrm{mg} / \mathrm{L}$ of $\mathrm{Co}(\mathrm{II})$ and $5000 \mathrm{mg} / \mathrm{L} \mathrm{of} \mathrm{Ni}(\mathrm{II}), \mathrm{pH}=6.2$ and $0.5 \mathrm{M} \mathrm{SO}_{4}{ }^{2}$.

- The McCabe-Thiele diagram shows that at an $\mathrm{A} / \mathrm{O}$ phase ratio of $1 / 2$, four theoretical stages are needed to separate cobalt from a solution contain- ing $500 \mathrm{mg} / \mathrm{L} \mathrm{Co(II)}$ and $5000 \mathrm{mg} / \mathrm{L} \mathrm{Ni(II)}$ in $0.5 \mathrm{M} \mathrm{SO}_{4}{ }^{2-}$ medium.

- The counter-current simulation confirms the

McCabe-Thiele prediction and shows that four stages are enough to reduce the cobalt concentra- tion from $500 \mathrm{mg} / \mathrm{L}$ to $2 \mathrm{mg} / \mathrm{L}$.

- The raffinate contains $83 \%$ of the inlet nickel with a purity of $99.9 \%$.

\section{Acknowledgments}

Nadia Belhadj gratefully acknowledges to the High teaching and Scientific research ministry, Algeria its PhD fellowschip (PNE), the University of Science and Technology of Oran (USTOMB), Algeria and the EPSECG, Universitat Politécnica de Catalunya.

The authors also thank Professor Ahmed Benahmed for English language corrections.

\section{Funding}

This work was supported by the Spanish Ministry of Economy and Competitiveness, MINECO grant number [CTM201783581-R].

\section{References}

[1] Geological Survey U.S.. 2017, Mineral commodity summaries 2017: U.S. p 52-114. doi:10.3133/ 70180197. ISBN 978-1-4113-4104-3.

[2] Report on critical raw materials for the EU. Ref. Ares (2015) 1819503 29/ 04/2015.

[3] Huang, Y.; Han, G.; Liu, J.; Chai, W.; Wang, W.; Yang, S.; Su, S. (2016) A step wise recovery of metals from hybrid cathodes of spent Li-ion batteries with leaching-flotation- precipitation process. Journal of Power Sources, 325: 555- 564. doi:10.1016/j.jpowsour.2016.06.072.

[4] Bertuol, D.A.; Machado, C.M.; Silva, M.L.; Calgaro, C. O.; Dotto, G.L.; Tanabe, E.H. (2016) Recovery of cobalt

from spent lithium-ion batteries using supercritical carbon dioxide extraction. Waste Manage, 51: 25-245. doi:10.1016/j.wasman.2016.03.009.

[5] Kang, J.; Senanayake, G.; Sohn, J.; Shin, S.M. (2010) Recovery of cobalt sulfate from spent lithium ion bat- teries by reductive leaching and solvent extraction with Cyanex 272. Hydrometallurgy, 100: 168-171. doi:10.1016/j.hydromet.2009.10.010.

[6] Wang, F.; He, F.; Zhao, J.; Sui, N.; Xu, L.; Liu, H. (2012) 
Extraction and separation of cobalt(II), copper(II) and manganese(II) by Cyanex272, PC-88A and their mix- tures. Separation and Purification Technology, 93: 8-14. doi:10.1016/j.seppur.2012.03.018.

[7] Jha, M.K.; Kumari, A.; Jha, A.K.; Kumar, V.; Hait, J.; Pandey, B.D. (2013) Recovery of lithium and cobalt from waste lithium ion batteries of mobile phone. Waste Manage, 33: 1890-1897. doi:10.1016/j. wasman.2013.05.008.

[8] Joulié, M.; Laucournet, R.; Billy, E. (2014) Hydrometallurgical process for the recovery of high value metals from spent lithium nickel cobalt aluminum oxide based lithium-ion batteries. Journal of Power Sources, 247: 551-555. doi:10.1016/j.jpowsour.2013.08.128.

[9] Babakhani, A.; Rashchi, F.; Zakeri, A.; Vahidi, E. (2014) Selective separation of nickel and cadmium from sulfate solutions of spent nickel cadmium batteries using mixtures of D2EHPA and Cyanex 302. Journal of Power Sources, 247: 127-133. doi:10.1016/j.jpowsour.2013.08.063.

[10] Joo, S.-H.; Shin, D.; Oh, C.H.; Wang, J.-P.; Shin, S.M. (2016a) Extraction of manganese by alkyl monocar- boxylic acid in a mixed extractant from a leaching solution of spent lithium-ion battery ternary cathodic material. Journal of Power Sources, 305: 175-181. 10. 1016/j.jpowsour.2015.11.039.

[11] Joo, S.-H.; Shin, D.; Oh, C.H.; Wang, J.-P.; Senanayake, G.; Shin, S.M. (2016b) Selective extraction and separa- tion of nickel from cobalt, manganese and lithium in pretreated leach liquors of ternary cathode material of spent lithium-ion batteries using synergism caused by Versatic 10 acid and LIX 84-I. Hydrometallurgy, 159: 65-74. doi:10.1016/j.hydromet.2015.10.012.

[12] Meshram, P.; Abhilash, Pandey, B.D.; Mankhand, T.R.; Deveci, H. (2016) Acid baking of spent lithium ion batteries for selective recovery of major metals: a two- step process. Journal of Industrial and Engineering Chemistry, 43: 117-126. doi:10.1016/j.jiec.2016.07.056.

[13] Hu, J.; Zhang, J.; Li, H.; Chen, Y.; Wang, C. (2017) A promising approach for the recovery of high value-

SEPARATION SCIENCE AND TECHNOLOGY

521

added metals from spent lithium-ion batteries. Journal of Power Sources, 351: 192-199. doi:10.1016/j. jpowsour.2017.03.093.

[14] Torkaman, R.; Asadollahzadeh, M.; Torab-Mostaedi, M.; Maragheh, M.G. (2017) Recovery of cobalt from spent lithium ion batteries by using acidic and basic extractants in solvent extraction process. Separation and Purification Technology, 186: 318-325. doi:10.1016/j.seppur.2017.06.023.

[15] Marafi, M.; Stanislaus, A. (2003) Options and processes for spent catalyst handling and utilization. Journal of Hazardous Materials, 101: 123-132. doi:10.1016/S03043894(03)00145-6.

[16] Valverde, I.M.; Frontino, P.J.; Afonso, J.C. (2008) Hydrometallurgical route to recover molybdenum, nickel, cobalt and aluminum from spent hydrotreating catalysts in sulphuric acid medium. Journal of Hazardous Materials, $160: 310-317$. doi:10.1016/j. jhazmat.2008.03.003.

[17] Banda, R.; Sohn, S.H.; Lee, M.S. (2012) Process develop- ment for the separation and recovery of Mo and Co from chloride leach liquors of petroleum refining catalyst by solvent extraction. Journal of Hazardous Materials, 1 (6): $213-214$. doi:10.1016/j.jhazmat.2011.12.078.

[18] Banda, R.; Nguyen, T.H.; Sohn, S.H.; Lee, M.S. (2013)

Recovery of valuable metals and regeneration of acid from the leaching solution of spent HDS catalysts by solvent extraction. Hydrometallurgy, 133: 161-167. doi:10.1016/j.hydromet.2013.01.006.

[19] Meshram, P.; Pandey, B.D.; Mankhand, T.R. (2014) Extraction of lithium from primary and secondary sources by pretreatment, leaching and separation: a comprehensive review. Hydrometallurgy, 150: 192208. doi:10.1016/j.hydromet.2014.10.012.

[20] Hejazi, L.; Mohammadi, D.E.; Yamini, Y.; Brereton, R.G. (2004) Solid-phase extraction and simultaneous spectro- photometric determination of trace amounts of $\mathrm{Co}, \mathrm{Ni}$ and $\mathrm{Cu}$ using partial least squares regression. Talanta, 62: 185-191. doi:10.1016/S0039-9140(03)00412-0.

[21] HadjYoucef, M.; Benabdallah, T.; Reffas, H. (2015) Cloud point extraction studies on recovery of nickel (II) from highly saline sulfate medium using salicylide- neaniline mono-Schiff base chelating extractant. Separation and Purification Technology, 149: 146-155. doi:10.1016/j.seppur.2015.05.034.

[22] Chung, N.H.; Tabata, M. (2004) Salting-out phase separa- tion of the mixture of 2- propanol and water for selective extraction of cobalt(II) in the presence of manganese(II), nickel(II), and copper(II). Hydrometallurgy, 73: 81-89. doi:10.1016/j.hydromet.2003.08.003.

[23] Sun, X.Q.; Peng, B.; Ji, Y.; Chen, J.; Li, D.Q. (2009)

Chitin (chitosan)/cellulose composite biosorbents pre- pared using ionic liquid for heavy metal ions adsorp- tion. AIChE Journal. American Institute of Chemical Engineers, 55: 2062-2069. doi:10.1002/aic.11797.

[24] Ribeiro, C.P., Jr; Costa, A.O.S.; Lopes, I.P.B.; Campos, F.F.; Ferreira, A.A.; Salum, A. (2004) Cobalt extraction and cobaltnickel separation from a simulated indus- trial leaching liquor by liquid surfactant membranes using Cyanex 302 as carrier. Journal of Membrane Science, 241: 45-54. doi:10.1016/j.memsci.2004.03.038.

[25] Yang, Y.Z.; Zhu, T.; Xia, C.B.; Xin, X.M.; Liu, L.; Liu, Z.

Y. (2008) Study on the extraction of cobalt and nickel from NH4SCN solution by Winsor II microemulsion system. Separation and Purification Technology, 60: 174-179. doi:10.1016/j.seppur.2007.08.006.

[26] Soldenhoff, K.; Shamieh, M.; Manis, A. (2005) Liquidliquid extraction of cobalt with hollow fiber contactor. Journal of Membrane Science, 252: $183-194$. doi:10.1016/j.memsci.2004.12.008.

[27] Bond, A.H.; Dietz, M.L.; Rogers, R.D. (1999) Progress in metal ion separation and preconcentration: an overview. in Metal Ion Separation and Preconcentration: Progress and Opportunities, (editors) Bond, A.H.; Dietz, M.L.; Rogers, R. D., American Chemical Society: Washington, DC. 2-12. 
[28] Devi, N.B.; Nathsarma, K.C.; Chakravortty, V. (1998) Separation and recovery of cobalt II/and nickel II/from sulphate solutions using sodium salts of D2EHPA, PC 88A and Cyanex 272. Hydrometallurgy, 49: 47-61. doi:10.1016/S0304386X(97)00073-X.

[29] Sarma, P.V.R.B.; Reddy, B.R. (2002) Liquid-liquid extraction of nickel at macro-level concentration from sulphate/chloride solutions using phosphoric acid based extractants. Minerals Engineering, 15: 461-464. doi:10.1016/S0892-6875(02)00063-8.

[30] Kumbasar, R.A. (2009) Selective extraction and con- centration of cobalt from acidic leach solution contain- ing cobalt and nickel through emulsion liquid membrane using PC-88A as extractant. Separation and Purification Technology, 64: 273-279. doi:10.1016/ j.seppur.2008.10.011.

[31] Mondal, S.; Kumar, V.; Sharma, J.N.; Hubli, R.C.; Suri, A.K. (2012) Evaluation of n-octyl(phenyl)phosphinica- cid (OPPA) as an extractant for separation of cobalt(II) and nickel(II) from sulphate solutions. Separation and Purification Technology, 89: 66-70. doi:10.1016/j. seppur.2012.01.015.

[32] Tsakiridis, P.E.; Agatzini, S.L. (2004) Process for the recovery of cobalt and nickel in the presence of mag- nesium and calcium from sulphate solutions by Versatic 10 and Cyanex 272. Minerals Engineering, 17: 535-543. doi:10.1016/j.mineng.2003.12.003.

[33] Park, K.H.; Reddy, B.R.; Jung, S.H.; Mohapatra, D. (2006) Transfer of cobalt and nickel from sulphate solutions to spent electrolyte through solvent extraction and strip- ping. Separation and Purification Technology, 51: $265-$ 271. doi:10.1016/j.seppur.2006.02.007.

[34] Hachemaoui, A.; Belhamel, K. (2017) Simultaneous extraction and separation of cobalt and nickel from chloride solution through emulsion liquid membrane using Cyanex 301 as extractant. International Journal of Mineral Processing, 161: 7-12. doi:10.1016/j. minpro.2017.02.002.

[35] Kursunoglu, S.; Ichlas, Z.T.; Kaya, M. (2017) Solvent extraction process for the recovery of nickel and cobalt from Caldaglaterite leach solution: the first bench scale study. Hydrometallurgy, 169: 135-141. doi:10.1016/j. hydromet.2017.01.001.

[36] Weng, J.; Wang, C.; Li, H.; Wang, Y. (2006) Novel quaternary ammonium ionic liquids and their use as dual solventcatalysts in the hydrolytic reaction. Green Chemistry: an International Journal and Green

Chemistry Resource: GC, 8: 96-99. doi:10.1039/ B508325G.

[37] Sun, X.; Ji, Y.; Zhang, L.; Chen, J.; Li, D. (2010) Separation of cobalt and nickel using inner synergistic extraction from bifunctional ionic liquid extractant (Bif-ILE). Journal of Hazardous Materials, 182: 447- 452. doi:10.1016/j.jhazmat.2010.06.052.

[38] Coll, M.T.; Fortuny, A.; Kedari, C.S.; Sastre, A.M. (2012) Studies on the extraction of Co(II) and Ni(II) from aqueous chloride solutions using Primene JMT- Cyanex272 ionic liquid extractant. Hydrometallurgy, 125 (126): 24-28. doi:10.1016/j.hydromet.2012.05.003.

[39] Miguel, E.R.S.; Vital, X.; Gyves, J. (2014) Cr(VI) transport via a supported ionic liquid membrane containing CYPHOS IL101 as carrier: system analysis and optimiza- tion through experimental design strategies. Journal of Hazardous Materials, 273: 253-262. doi:10.1016/j. jhazmat.2014.03.052.

[40] Leyma, R.; Platzer, S.; Jirsa, F.; Kandioller, W.; Krachler, R.; Keppler, B.K. (2016) Novel thiosalicy- late-based ionic liquids for heavy metal extractions. Journal of Hazardous Materials, 314: 164-171. doi:10.1016/j.jhazmat.2016.04.038.

[41] Guo, X.; Yao, W.; Chen, Y.; Fan, J.; Zhao, Y.; Wang, J. (2017) PEG-functionalized ionic liquids: a class of liquid materials for highly efficient extraction of rare earth metals from aqueous solutions. Journal of Molecular Liquids, 236: 308-313. doi:10.1016/j.molliq.2017.04.044.

[42] Platzer, S.; Kar, M.; Leyma, R.; Chib, S.; Roller, A.; Jirsa, F.; Krachler, R.; MacFarlane, D.R.; Kandioller, W.; Keppler, B. K. (2017) Task-specific thioglycolate ionic liquids for heavy metal extraction: synthesis, extraction efficacies and recycling properties. Journal of Hazardous Materials, 324: 241-249. doi:10.1016/j.jhazmat.2016.10.054.

[43] Nguyen, V.T.; Lee, J.-C.; Kim, M.-S.; Kim, S.-K.; Chagnes, A.; Cote, G. (2017) Sustainable extraction and separation of precious metals from hydrochloric media using novel ionic liquid-in-water microemulsion. Hydrometallurgy, 171: 344-354. doi:10.1016/j.hydromet.2017.06.003.

[44] Wojciechowska, A.; Wieszczycka, K.; Wojciechowska, I. (2017) Pb(II) removal with hydrophobic quaternary pyr- idinium salt and methyl isobutyl ketone. Hydrometallurgy, 171: 206-212. doi:10.1016/j.hydromet.2017.05.017.

[45] Obón, E.; Coll, M.T.,.; Sastre, A.M. (2017)

Experimental and modelling studies of neodymium solvent extraction from chloride media with methyltri(octyl/decyl)ammonium oleate ionic liquid diluted in kerosene. Hydrometlurgy, 174: 216-226. doi:10.1016/j. hydromet.2017.10.021.

[46] Pavón, S.; Coll, M.T.,.; Sastre, A.M. (2018) 367Neodymium recovery from NdFeB magnet wastes using Primene 81R C Cyanex 572 IL by solvent extrac- tion. Journal of Environmental Management, 222: 359- 367. doi:10.1016/j.jenvman.2018.05.054.

[47] Pavón, S.; Coll, M.T.,.; Sastre, A.M. (2018) Rare earths separation from fluorescent lamp wastes using ionic liquids as extractant agents. Waste Management, 82: 241-248. doi:10.1016/j.wasman.2018.10.027.

[48] Zarrougui, R.; Mdimagh, R.; Raouaf, N. (2018) Highly efficient extraction and selective separation of uranium (VI) from transition metals using new class of undi- luted ionic liquids based on H-phosphonate anions. Journal of Hazardous Materials, 342: 464-476. doi:10.1016/j.jhazmat.2017.08.057.

[49] Global, C.T.M. Technical data sheet primene JMT. http:// globalctm.co.kr/product/primene/primene_jm-t.php

[50] Dow Chemical Company. (2017). Safetydata sheet pri- mene JM-T amine. https//www.dow.com/en-us/ eLibrary\#q=amines

[51] Hexion. (2015). Technicaldata sheet Versatic acid 10. http://www.hexion.com/en-US/product/versatic-acid-10

[52] Kyung-Ho, P.; Debasish, M. (2006) Process for Cobalt Separation and Recovery in the Presence of Nickel fromSulphate Solutions by Cyanex 272. Metals and Materials International, 12 (5): 441-446. doi:10.1007/ BF03027712.

[53] Gotfryd, L.; Szymanowski, J. (2004) Recovery of zinc(II) from acidic sulfate solutions. Simulation of counter-cur- rent extraction-stripping process. Physicochemical Problems of Mineral Processing, 38: 113-120. 
[54] Gotfryd, L.; Cox, M. (2006) The selective recovery of cadmium(II) from sulfate solutions by a counter- current extraction-stripping process using a mix- ture of diisopropylsalicylic acid and Cyanex R471X. Hydrometallurgy, 81: 226-233. doi:10.1016/ j.hydromet.2006.01.001.

522 M. HADJ YOUCEF ET AL. 